\title{
Reconceptualizing Anti-Oppressive Pedagogy: A Lesson from the Other
}

\author{
Rebeca Heringer \\ University of Manitoba \\ heringer@myumanitoba.ca
}

\begin{abstract}
Two decades after Kumashiro's (2000) groundbreaking work, the postulates of anti-oppressive pedagogy are still in urgent need. Despite the contributions made by Kumashiro, this paper outlines how even attempts of anti-oppressive pedagogies can fall short of welcoming the Otherwhich can be clearly observed when focusing on Black refugee students in Canada. In the pursuit of an anti-racism pedagogy, I revisit Kumashiro's revision of anti-oppressive tenets through the lenses of post-structural philosophy and psychoanalytical input and propose the ethics of hospitality, as articulated by Derrida (2000a, 2000b) and Ruitenberg (2016), not only as a necessary complement to that earlier work but also a pressing reconceptualization of modern education.
\end{abstract}

\section{Introduction}

La peau du visage est celle qui reste la plus nue, la plus dénuée ... il y a dans le visage une pauvreté essentielle. (Levinas, 1982, p. 80)

In the midst of innumerous possible ways of defining education, Ruitenberg (2016) conceptualizes it as an act of unlocking the world to children who have involuntary been born to it. As the author points, it is the responsibility of those who are already in the world to welcome the newcomers, "unlocking" their access to it. Todd (2003) follows the same idea, pointing out that the "curriculum involves introducing [students] to new encounters" (p. 18) from where they will learn to become. Although we must be aware of the dangers behind the "learnification" ideology (Biesta, 2009, 2016), education may be conceptualized as the encounter between the student and teacher, who has the keys to guide newcomers to the world and thus enable them to become active subjects with agency (Ruitenberg, 2011a, 2016). In a nutshell, "this balance between children's freedom and the constraints imposed upon them is at the heart of education" (Ruitenberg, 2016, p. 2). Ruitenberg's metaphor gains even more strength when conceptualizing education to refugee students, who are involuntary migrants to a new country. Whatever hinders students, or in Ruitenberg's words, whatever locks the world preventing others to gain access to it, is a form of oppression which has to be fought against (Kumashiro, 2000). However, as I will explore in this paper, the job of the teacher is not merely to unlock the world as it is, but as it is not.

Teaching is never a simple, neutral delivery of content to a body of students. Rather, teaching is "a psychic event for the teacher" (Britzman, 1998, p. 134) who inevitably responds to students based on one's own set of assumptions, privileges and biases. Tied to this is the fact that Black refugees are not merely "culturally diverse" students, as may often be proclaimed. Although every student constitutes an "Other" for the teacher, it is important to note that race has, at least 
since the Enlightenment, placed Blacks in a less-than-human category in the eyes of whites, having major consequences in a racialized society as we live in (Mbembe, 2017; Walcott \& Abdillahi, 2019). While social class or language can pass by unnoticed in the first moment, students' race is never invisible to the teacher but is rather always there since their very first encounter. Their face, exposed to one's eyes, thus always renders the Other vulnerable, as Levinas (1982) well observed.

Obviously I do not mean in any ways to undermine the importance or hierarchize the oppression of other minority groups' claims and oppression. However, it is important to note that the ubiquitous culturalization of race (thus the diminishment of the meaning of culture itself) is anchored on historical and systemic racism and white supremacy that remains pervasive in the country. As Leonardo (2009) summarizes, "culture is comprised of rituals, practices, and artifacts, whereas race is an idealist categorization of people based on phenotypes. Marginalized people have created rich inventories of culture, whereas race is imposed by domination" (p. 58). Consequently, whites usually avoid or reject the concept of race and choose instead a more comfortable discourse, one in which whiteness is not only maintained but also centralized (Dei, 1999; DiAngelo, 2018; Leonardo, 2009).

The problem of Western metaphysics, thus, becomes fundamental to this work, as the myth of the origin (Peters \& Biesta, 2009) pervades the classroom through the discourse of whiteness and Canadianism (which ultimately implies whiteness as well). As a by-product of the historical and pervasive anti-Black racism in the country, Black students have been denied their state of purity and innocence, rather becoming associated with danger and inferiority while "not seeing themselves reflected and celebrated in the curriculum" (Maynard, 2017, p. 216), an issue that is further problematized when these students hold refugee status. Indeed, several studies point out how racism is experienced by refugees in Canada in great scale, not only from peers but also from teachers (Baker, Price \& Walsh, 2016; Guo, Maitra \& Guo, 2019; Stewart, 2011). But despite the correlation of racism and students' well-being, the issue hardly ever receives attention longer than a few words before the researcher moves on to another point.

While one may think that being received into a "peaceful" country and having access to education is enough, the physical presence of refugee students does not make a classroom necessarily a safe or just place for them. The idea of Canada being a hostile environment for refugees may not be as common internationally-or even within its own society-partially "because Canada has generated in its self-narrative a description of a generous, liberal, and progressive society that has overcome its earlier bigotries and prejudices" (Battiste, 2019, p. $125)$. But the fact is that while schooling may be the symbol of democracy for some, it is a symbol of oppression for others (Apple, 2014). So, if being at school is not necessarily a welcoming experience, what should educators' responsibility when receiving Black refugees be? Based on Kumashiro's (2000) theory of anti-oppressive education, this paper will begin by discussing three overlapping and broad conceptual frameworks that currently inform educational approaches towards diverse students in the pursuit of social justice. While both Kumashiro (2000) and Todd (2003)-whose work will also be very helpful here-are focused on the impact of anti-oppressive/ethical education on the learner, that is, how students are to be engaged with otherness, I maintain that teachers themselves ought to be active learners of this pedagogy as 
well. In addition, although Kumashiro writes from the U.S. context, the ways in which his work clearly resonates in the Canadian context will be depicted here. As the author argues, each of these frameworks by themselves are not enough in the pursuit of anti-oppressive education. Indeed, despite his groundbreaking work, Kumashiro does not provide the necessary focus on race and racism that is so necessary when conceptualizing anti-racism education. In addition, although the author only refers to post-structural and psychoanalytical theories at the end of his paper, I will highlight here how those are pivotal when deconstructing the first three approaches as well, thus making room for what appears to be a major gap in current educational practices, especially when focused on Black refugee students.

Finally, through the lens of post-structuralism and an ethics of hospitality (Derrida, 2000a, 2000b; Ruitenberg, 2016), I argue that rather than a ready-made set of interventions, expectations and assumptions, education must be conceptualized as an act of openness to the unknown and otherness welcomed as a condition to education itself. In addition, it will be observed that justice, although not an utopic goal, is never achievable-which does not mean not striving for it, but the contrary. Rather, the decentralization of the teacher is what appears to be the first (and continuous) key for a classroom where Black refugee students can in fact be active subjects with agency.

\section{Education for the Other}

In the first framework that Kumashiro (2000) outlines, oppression in schools is conceptualized in two ways: external actions and inactions as well as internal assumptions and expectations. An anti-oppressive education, thus, seeks to remediate the harm caused by providing instead a space that is helpful, safe, affirming, therapeutic, supportive, etc. This first approach appears in the literature with different labels (e.g. empathy, ethics of care, compassion, resilience theory, etc.), but they all have a common denominator which is an education (theoretically) designed for the Other, for the needs of the Other. Once needs have been identified, educators, sensitized to how challenging and traumatic students' lives have been, eagerly seek to provide support and help to eliminate barriers so that refugee students can enjoy the same educational and life opportunities as Canadians.

The commonly adopted Bronfenbrenner's (1979) theory of human development (or similar models) in research focused on refugee students, points to how multilayered the experience of the refugee student can be, offering schools a myriad of elements to take into consideration in order to support them and their families, ranging from their academic difficulties all the way to health and housing (Brewer \& McCabe, 2014; Kanu, 2008; Stewart, 2011, 2012; Stewart et al., 2019; Tavares \& Slotin, 2012; Walker \& Zuberi, 2019; Wilkinson, 2002). Surely, to a certain degree it is important to be aware of the challenges faced by minority groups, especially those who have to deal with a plethora of discoveries and adaptations after arriving in the country. Leonardo (2009), for example, observes that schools often hold deficit perspectives of parents of immigrant children for not getting more involved with their education without realizing that the family feels hostilized for not being native English speakers. Indeed, language has been one of the major focus of studies with refugee students in Canada, identifying their "gaps", and tracing 
strategies to support them and their families in those challenges (Asadi, 2014; Brewer \& McCabe, 2014; Dachyshyn \& Kirova 2011; Lee, 2016; MacNevin, 2012; Walsh et al., 2011). Another way in which education under this framework would combat oppression is through the recognition and affirmation of students' differences by building on their religious, national and linguistic identities as well as their (presumed) personal characteristics such as culture, motivation, resilience and hope (Hird-Bingeman, McCabe, \& Brewer, 2014; Stewart, 2011; Tavares \& Slotin, 2012). That is, in order to involve all students in the classroom the teacher must tailor their practices according to the student population and specially "acknowledge the realities of day-to-day life that can hinder one's ability to learn” (Kumashiro, 2000, p. 29). While this framework enables educators not only to become aware of how different one's life experiences can be but also to actively seek to contribute to students' and their families wellbeing-both which, at the first moment, would appear as strengths of this approach-there are many caveats to it that need to be discussed. But before I address those limitations, it is remarkable how, in related literature, race and racism is hardly ever addressed, is left at the margins, or is replaced by less polemical (i.e. color-blind) terms such as culture or ethnicity. The avoidance of what is considered problematic (i.e. race) is also expressed through the frequent attribution of student's "failure" or "dropout" to the student's family or home environment (Dei, 1996, 2008). Although I do not deny the importance of supporting students' experiences beyond the classroom or taking into consideration the plethora of challenges that students bring with them to school, race is rarely discussed as being central in the schooling experiences of refugees, let alone the way in which race shapes teachers' perception and consequently welcoming of the Other, notwithstanding its major effects on students' well-being (for a few exceptions see Baker, Price, \& Walsh, 2016; Guo, Maitra \& Guo, 2019; Schroeter \& James, 2015; Walker \& Zuberi, 2019). In fact, the teacher-student relationship, when addressed, is most of the times (if not always) in terms of a unilateral relationship, that is, how the presence of the refugee student impacts the teacher and consequently how educators are to respond (e.g. "How should educators respond to disclosure?" or "How do I know if I am experiencing vicarious trauma?", in Tavares \& Slotin, 2012).

Regardless of the label given, this approach either fails to name a main issue in education (i.e. racism), disguises the problem with more manageable terms, or attributes students' (perceived) schooling barriers to other realms, which leaves the (white) teacher as centralized subject-and that is where post-structuralism can help deconstruct such ideas. A major problem in Western society, at least since the Enlightenment, is how our minds are projected to think in binary terms and to see the self as the origin (Fagan, 2013; Hall, 1992; Peters \& Biesta, 2009). The Other, thus, always emerges as an interruption of the self, that which I cannot comprehend, which causes discomfort. Our first attempt, then, is to try to bring the Other to the realm of the self, to understand the Other. Knowledge, thus, becomes an attempt of possession, to reduce that which goes beyond the self to that which I can grasp, being consequently not only a violent act against the Other's uniqueness but an attempt to eliminate alterity, which is necessary for community (Dei, 2008; Fagan, 2013; Levinas, 1972, 1982).

Conversely, as Kumashiro (2000) emphasizes, "teaching involves a great degree of unknowability" (p. 31), so trying to generalize experiences or characteristics runs the risk of defining the limits of the (objectified) Other. This can be noticed, for example, with the 
commonly adopted resilience theory used in the work with refugee students. Stewart (2011), for instance, recognizes how not every refugee student demonstrates psychological issues. When talking to her research participants, the author points out that despite her coming to the interview moment with an assumed idea of resilience, for many students "it seemed that they had put the war behind them and then moved on with life in Canada" (p. 96). Fantino and Colak (2001), working with refugee children who did not fit the common assumptions about them, also observe that "the perception of the resilient and adaptable refugee child needs to be reexamined" (p. 591). Thus, despite the importance of conducting research with minority students as an opportunity for them to voice their experiences and thus help educators improve their schooling experience, attributing characteristics to them a priori is in fact a totalitarian relationship, one that seeks to determine who the Other is or can be (Levinas, 1972, 1982, 1934/1997), hence impinging on students' agency.

Although the advancement of technology, increasing migrations and shifts in social theory and human sciences may have contributed to identity hybridity and an apparent decentralization of the Cartesian subject (Hall, 1992), being together does not eliminate hostility towards the Other. Discussing the roots of the concept of xenophobia, Derrida (2000a) observed that xenos not only means that which is heterogeneous, but also the relation between the citizen and the foreigner. Identity may have turned into a "code word for stability" (Morris, 2003, p. 197), however, regardless of the proximity, the presence of the Other consists of an inevitable violent attack against one's self (Fagan, 2013; Freud, 1923/2018; Todd, 2003). After all, "a foreigner can be a parricide only when he is in some sense within the family" (Derrida, 2000a, p. 7). Consequently, discourses of care (Noddings, 1984) and compassion (Carson \& Johnston, 2000), for example, touch on a more basic problem which is the projection of the self to the Other (Todd, 2003). An ethics of care, as proposed by Noddings (1984) for instance, is not sufficient to empower students as active subjects with agency because its emphasis "is not on the subject but on the relation between subject and other" (Ruitenberg, 2016, p. 11, italics in the original)-a relation which is ultimately egoistic (Todd, 2003). In addition, there is a major risk that this framework serves to reinforce the white savior myth, a condescending relation with the Other who is perceived as less fortunate, less advanced, and lacking attributes to be as white/Canadian, which, in turn, "implies that the Other is the problem" (Kumashiro, 2000, p. 30; cf. also Heron, 2007).

Surely, equity is a noble goal that we must pursuit in all realms of life and especially through education (Gorski, 2019). However, when education is conceptualized for the Other not only is the teacher-student relationship potentially patronizing, but this helping imperative may in fact derivate from one's necessity of the Other in order to sustain one's (white Canadian) self, one's own idea of (white Canadian) superiority and (white Canadian) centrality, "which holds the promise of wholeness" (Heron, 2007, p. 8). All in all, a positivistic perspective of refugee students, regardless of potential "good intentions", tries to define the fluid boundaries of the Other while leaving the white self as the foundation whence all goodness springs. So if this is not enough, how can teachers welcome Black refugee students?

\section{Education about the Other}


If in the first framework the educator tries to take the self to the Other through affirmation of the difference, in education about the Other the teacher seeks to bring the Other to the self (Todd, 2003). As Kumashiro (2000) observes, oppression is here conceptualized as two kinds of harmful knowledge: normal and normative definitions as well as stereotypes and myths. More than just recognizing alterity, as the first framework proposed, an anti-oppressive pedagogy here would be translated through inclusion and integration, that is, teaching all students what needs to be known about the Other so as to generate empathy among them and "normalize difference and Otherness" (Kumashiro, 2000, p. 33). This framework has long been the driving force of many educational research and practice with immigrant students, remaining strongly under the umbrella of multiculturalism. Tavares and Slotin (2012), for example, offer a long list of emotional blocks to learning and strategies educators are to adopt in order for learners to feel included in the classroom. A great amount of information about refugee students and their families, determinant factors of their success and well-being are provided so that education can be motivating, inclusive of the student's culture and background experience.

Kumashiro (2000), however, notes three weaknesses of this framework: essentializing the Other, positioning the Other as the expert to explain "their group's" experience, and once again, trying to grasp full knowledge of the Other-which is not only impossible but undesirable (Levinas 1972, 1982). Notwithstanding, these three limitations are in fact intertwined and stemming from the same metaphysical issue: "a hierarchical axiology in which the origin is designated as pure, simple, normal, standard, self-sufficient, and self-identical, in order then to think in terms of derivation, complication, deterioration, accident, etcetera" (Peters \& Biesta, 2009, p. 21, italics in the original). Indeed, a major problem with this approach is that it "suggests that the self's ego boundaries are flexible enough to incorporate another into its reality without having to project anything upon the other" (Todd, 2003, p. 57). In the midst of such effort to eliminate differences and unify identities (Hall, 1992), it is necessary to observe whose voice is behind this pursuit of homogeneity. That is, in this attempt to blend the differences and promote a color-blind, transnational discourse, the desire is ultimately for whiteness (Heron, 2007; Leonardo, 2009). Furthermore, having one student be the representative of a group-e.g. Blacks, refugees-not only puts the student (who may already be feeling oppressed) on the spot (hooks, 1994), adding on their burden, but also suggests that the (white Canadian) educator has nothing to do with their oppression-e.g. racism, (neo)colonialism.

In the early $20^{\text {th }}$ century, Jane Addams (1908/2017) already pointed out the discrepancy immigrant children can find between their homes and their new school-which may have contributed to the development of what anthropologists later coined the "cultural discontinuity hypothesis" (Ogbu, 1982). Indeed, being a widely spread theory in education, cultural discontinuity is understood as a major source of students' difficulties when immersed in a new context (Boulanger, 2019; Ogbu, 1982). The original hypothesis was suggested by anthropologists who observed how the home experiences of young children differed greatly from their new classroom and social experiences, which would be reflecting on students' academic and psychological challenges (Boulanger, 2019; Tyler et al., 2008; Ogbu, 1982). Consequently, culture is believed to play a vital role in one's cognitive development, human activity and thought processes (Ogbu, 1982), thus posing a great challenge in the lives of those who experience a rupture in their ways of being, especially when it comes to minority groups 
(Bobowik et al., 2014; Tyler et al., 2008). Although Ogbu (1982) suggested that all students experience home-school discontinuities throughout their schooling, such discrepancies are considered more pronounced for ethnic minority students (Tyler et al., 2008). As Tyler et al. argue, ethnocentric monoculturalism becomes a precursor to the cultural discontinuity experienced by many ethnic minorities, leading non-Western cultural values or belief systems to be the most affected.

The underlying idea behind education about the Other, then, is that by exposing all students to alterity and to a culturally diverse curriculum would generate the awareness that is needed to make everyone respect the diverse Other and achieve equitable education (James, 2009). If in the first framework, education would send out the necessary medicine to alleviate and meet the needs of the suffering Other, in this second moment education seeks to build a bridge so that the Other can join the dominant society in a healthy way. However, empathy is not a laden-free concept, as Kumashiro (2000) well observes. Although it may seem an honorable feeling, feelings "are not constitutive of nonviolence, of ethical interaction" (Todd, 2003, p. 51). As both authors note, emotion and commiseration can connect individuals and they have their importance. However, this rationale implies identification by way of imitation (Todd, 2003). That is, while empathy may appear as a morally correct form of togetherness, it in fact serves to reinforce the centralized and patronizing self-Other binary.

Multicultural education was developed as a panacea for celebrating cultural diversity, reducing prejudice and the promotion of equity pedagogy (Banks, 1993). Certainly multiculturalism had its value when it began as, for the first time, (some) aspects of (some) minority students' cultures could appear in the curriculum in a way that was not derogatory (Leonardo, 2009; Wilson, 2016). However, as Wilson (2016) illustrates, food, music and clothes are just the tip of the iceberg, not all that shapes one's being. When these aspects become the synonym for culture (and race) and all that is addressed in education, the basis (e.g. ontology, epistemology) remains unchallenged and students become essentialized (Gorski, 2019; James, 2009; Kumashiro, 2000). For example, one of the participants in Tecle and James's (2014) study reports the distressing situation she went through when the teacher asked the students to give a presentation about their native countries and bring in artifacts that would represent the "uniqueness and richness" of their culture (p. 153). As the participant observes, while for her classmates that was not an issue, she felt nervous and fearful to share stories about her family and "home country", which had undergone deep political issues. Not only was the student forced to present but, to make matters worse, she felt that she was listened to as "the poor refugee student", which made her resent even more having presented. On the one hand, while it is important for students of color to see their cultural and racial identities expressed in the curriculum, care must be taken not to try to promote a mirror curriculum which "alone cannot provide the conditions for ethics, that is, for a nonviolent relationship with the Other where the otherness of the Other is left intact and unharmed" (Todd, 2003, p. 40).

Moreover, concepts of inclusion and integration, although ubiquitous in educational research with refugees in Canada, are also not sufficient because they do not challenge dominant structures. Guo, Maitra and Guo (2019), for example, observe how racism is a major source of oppression among the refugees students who participated in their study in Western Canada. Not 
only did the children in that study report racial discrimination from their peers but also from their teachers, which made their situation even more distressing. Guo et al. emphasize that educators must not treat refugee students as a homogenous group with the same needs, as highlighted beforehand in the first framework. However, at the end the authors suggest that in order to better integrate refugee children in the school, "dispel negative preconceptions and alleviate prejudice ... educators must teach all children about refugees at school" (p. 98, my emphasis). The utmost importance of the teacher-student encounter is, one more time, substituted by external interventions that leave the educator's self centralized. In education about the Other, power remains unchallenged on the hands of those who already have it and can navigate the educational system with their privileges: looking, thinking and behaving "white like Canada" (Clarke, 1997; see also DiAngelo, 2018; Gorski, 2019; hooks, 2015; James, 2009; Leonardo, 2009). Education about the Other, thus, implies the myth of homogeneity and in a contradictory way. Canadians have long taken pride in being a mosaic society (as opposed to their melting pot neighbor), a place where different cultural groups can maintain their customs and traditions (James, 2009). Porter (1965) correctly challenged the assumption of non-hierarchy and coined the idea of a vertical mosaic. However, not only are differences hierarchically structured but also remain dictated by the dominant voice. In other words, incorporating the Other remains linked to an idea of originality (white Canadian) which gives shape to the mosaic: the Other is allowed to be, but only to the extent that the dominant society allows.

Of course, if we were to speak only in terms of culture, there must be a common culture (however pleonastic this may sound) for the sake of any society's cohesion. Notwithstanding, inclusion is often simply another term for "tolerance". To tolerate the Other implies hierarchy, power of one over the Other and hence not synonym for welcoming one's uniqueness (Fagan, 2013). Therefore, inclusion is also not enough in the struggle against oppression because it brings with it the idea that diversity must be incorporated or overcome, as a fort pedagogy (Donald, 2012) in which "outsiders must be either incorporated-brought inside to become like the insiders-or excluded in order for progress and development to take place in the necessary ways" (p. 101)-a rationale that clearly guided Selimos and Daniel (2017) in their research with refugee students in Ontario, for example. In addition, as Boler and Zembylas (2003) highlight, the concept of inclusion also hides the fact that ultimately it is the dominant group who decides what can or cannot be tolerated and when difference is worth naming (which would render it importance).

In education about the Other, the dominant voice naturalizes some created ideas (i.e. those which maintain white privilege, such as the English language superiority or Western rationality), while refusing others based on the argument that they are not real and thus not worth discussing (e.g. claiming that race, being a social construction, can simply be ignored or disbelieved). Indeed, it is necessary to observe how oppressive discourse can be and how that is constantly expressed in educational research and practice. Thinking just about terminology, for example, if race is taken to belong to the realm of culture together with other cultural expressions such as language, academic expectations, parental involvement, etc., why is it not addressed as often those other sub-categories? However, if race does not belong to culture, then the avoidance of the Other is outright. Now, if we grant that "ethnicity" encompasses race, then how would that be different from culture? It seems that a whole series of contradictions and complexities arise when concepts 
are used interchangeably with race, which would urge any scholar to look for better definitions. But what is truly ironical is how Western-minded educators are continually looking for sets of clear directions to hold on to but, when it comes to defining uncomfortable terms (i.e. terms that ultimately threat our power and wholeness), we suddenly become very comfortable with nebulous ideas.

Indeed, anti-oppressive education "requires disruptive knowledge, not simply more knowledge" (Kumashiro, 2000, p. 34). However, it is not merely knowledge of what is there, but what is not. It requires understanding that alterity has no beginning. In the genuine encounter with the Other we are not in relation with the Other, "we are relation" (Fagan, 2013, p. 119).

\section{Education that is Critical of Privileging and Othering}

In Kumashiro's (2000) third framework, oppression is not only defined by the segregation of the Other but also how schools privilege and legitimize dominant ideologies. Rather than trying to remediate the Other or to teach about the Other, educators and students are now invited to examine how the "normal" came to be the norm, challenge these assumptions, and critique their own positionalities. This framework started to gain strength with the reconceptualization of curriculum movement which emerged in the late 1970s and continues until today under the umbrella of critical pedagogy (Pinar, 1977/2017).

One of the greatest exponents of this approach, Paulo Freire, strongly argued that the curriculum has to be developed in dialogue with the Other. Even though most of his work is focused on adult literacy, Freire's contributions to education as a whole are undisputable. As Freire (1970/2017) argued, education remained throughout the decades an attempt to incorporate marginalized students into a pre-defined and rigid structure, but segregated students "cannot overcome their dependency by 'incorporation' into the very structure responsible for their dependency" (p. 181). In other words, Freire argued that students who are simply being for others, deprived of speaking and thus transforming the environment, are actually marginalized insiders, that is, they "are not marginal to the structure, but oppressed men within it" (p. 181). On a similar vein, Black refugee students may be physically present in the classroom like all the others, but by having their uniqueness hindered they become oppressed in that same structure that claims to be an empowering opportunity for them; for "to exist, humanly, is to name the world, to change it" (Freire, 1968/2018, p. 88, italics in the original).

As Kumashiro (2000) notices, under this approach education "should lead not only to empathy for the Other, but also to the ability and the will to resist hegemonic ideologies and to change social structures" (p. 38). With his work, Freire also provided an important critique to the white savior myth that has long pervaded Canadian education. Refugee children may arrive in Canada as a consequence of wars, famine, detention and other horrible circumstances in their home countries (Stewart, 2011, 2012), however, as previously discussed, "any attempt to 'soften' the power of the oppressor in deference to the weakness of the oppressed almost always manifests itself in the form of false generosity" (Freire, 1968/2018, p. 44). While accepting refugee students may be portrayed as a gesture of human rights, if it starts with the oppressor it will most likely serve their own egoistic interests, thus becoming a dehumanizing act (Freire, 1968/2018). 
Freire emphasized that students must not be simply treated as unfortunate people (p. 54) and that liberation takes place not through "pseudo-participation, but commitment involvement" (p. 69). Consequently, emancipatory education is not about mere integration of students, but transforming the structure so that students "can become 'beings for themselves"” (p. 74).

As aforementioned, Kumashiro's (2000) frameworks often appear overlapping each other in the literature. So although there seems to be a dearth of studies conducted specifically with Black refugee students in the Canadian context through the lens of critical pedagogy (one exception, for example, being Schroeter \& James, 2015), some of the existing related literature brings some features of the first framework while claiming to be a study done through the lens of critical race/social theory (Stewart, 2011; Tecle \& James, 2014). What these studies have in common is that they not only expose the inequities experienced by the refugee students but also draw attention to the source and maintainer of their oppression-although some in a more subtle ways than others. Students reveal feeling constrained by the system in which they are immersed, although finding ways to express themselves-such as through hip hop (Schroeter \& James, 2015). Students' parents are in general portrayed as both having high expectations of their children's academic achievement as well as not being very involved with their schooling-which is explained especially in terms "of their work schedules and the difficulties associated with resettlement” (Tecle \& James, 2014, p. 153).

Kumashiro (2000) notes, however, three limitations of this framework. First, it is important to keep in mind that oppression is not experienced in the same way by different people, regardless of apparent commonalities. This is particularly important in the development of a key tenet in critical race theory, intersectionality, which is fundamental when thinking about the oppression Black refugees face. A second limitation to take into consideration is that knowledge and critical thinking (or Freire's conscientização) do not necessarily lead to emancipatory action. Although both Kumashiro and Freire speak particularly about the consciousness-raising of students, it seems that the same is pertain to that of teachers'. On the one hand, as aforementioned, students may not wish to take action or speak up because of the oppression they have long faced, lack of trust, and the hopelessness that they will ever be effectively heard. On the other hand, even teachers who become aware of students' oppression will not necessarily be led to transformative action. The encounter with the Other disrupts the self, and the most natural tendency is that teachers, feeling the vulnerability of their power and control, will hold on firmly to their selfaffirmation (Todd, 2003). This leads to the third limitation of this approach, as Kumashiro (2000) highlights: the idea "that reason, and reason alone is what leads to understanding" (p. 39). Conversely, our beliefs, biases and assumptions are ingrained in the Western mind (Giroux, 1981; Peters \& Biesta, 2009; Tejeda, Espinoza, \& Gutierrez, 2003) and not necessarily different people will think in the same way, especially when such knowledge threatens one's sense of power. This can be observed, for example, when the refugee's claims of being oppressed for their race are not taken seriously by the teacher (Guo et al., 2019).

Freire (1968/2018) correctly argued that rather than objects or containers to be banked with knowledge, the oppressed must become the subject of education and "intervene critically in the situation which surrounds them" (p. 67). At the same time, the scholar recognized that "the oppressor knows full well that this intervention would not be to his interest" (p. 52).

Journal of Contemporary Issues in Education, 2020, 15(2), pp. 50-68. 
Notwithstanding, Freire placed greater responsibility on the oppressed, who "must confront reality critically" (p. 52), see the vulnerability of the oppressor (p. 64) and thus take the first step towards their own liberation. An expression of the challenge of this approach can be observed in the early Combahee River Collective (1977) statement:

Racial politics and indeed racism are pervasive factors in our lives did not allow us, and still does not allow most Black women, to look more deeply into our own experiences and, from that sharing and growing consciousness, to build a politics that will change our lives and inevitably end our oppression. (p. 3)

As it has been discussed in this paper, the status quo is comfortable for the white Canadian teacher (or even non-whites or non-Canadians who act in such manner) who is able to control the situation, enjoy their privileges and navigate through a system that works to their benefit. The minority student, on the other hand, arrives in a system where a prescribed education inhibits learners' expression (Freire, 1968/2018, p. 47), where they internalize a sense of selfdepreciation that the oppressors have of them (p. 63), which can then lead them to accept their exploitation (p. 64). Moreover, placing the responsibility on the oppressed is often linked to the idea that whites are passive in their dominance, as if they had received their privileges by birth and simply remained like that. Therefore, expecting the oppressed to fight against the pervasiveness of racism without first naming and deconstructing one's own whiteness will not magically transform classrooms into truly welcoming spaces for Black refugee students. Critical pedagogy takes into consideration the link between domination and psyche (Giroux, 1981), which is a vital component of anti-oppressive education. Although the extent to which racism can be an unconscious act will not be discussed here, critical pedagogy emphasizes "the diverse conditions under which authority, knowledge, values and subject positions are produced and interact within unequal relations of power; it also problematizes the ideologically laden and often contradictory roles and social functions that educators assume within the classroom" (Giroux, 2020, p. 91). Canada may try to conceal the oppression towards racially diverse refugee students, but that is nonetheless present, pervasive and likely even more powerful than in places where oppression is obvious to the world (Giroux, 1981).

Another limitation to this framework can be observed in Freire's conceptualization of dialogue, which is often found in research focused on "diverse students" under the concept of community (e.g. Sapon-Shevin, 2010; Stewart, 2011; Tavares \& Slotin, 2012). However, as previously observed, the physical presence of the Other does not necessarily generate community, nor does the voice of the Other represent democratic dialogue (Todd, 2003; Trifonas, 2005); in fact, community is not necessarily a good thing. As Dei (2005) argues, "a community can be a vehicle for perpetuating ideologies of race, class, gender, and sexuality" (p. 14). If the encounter with the Other happens through the projection of the self or the attempt to comprehend the Other, there is no genuine dialogue or community but just a reproduction of the self. A true relation, conversely, is always an act of violence because it involves a traumatic disruption of the self which is "a necessary condition of subjectivity" (Todd, 2003, p. 20). The question, thus, is rather the extent to which educators are willing to support the absence, the silence, the suspension, the cipher without deciphering.

Journal of Contemporary Issues in Education, 2020, 15(2), pp. 50-68. 


\section{Education that Changes Students and Society}

Kumashiro's (2000) overlapping frameworks evolve into a fourth approach to anti-oppressive education. Here oppression happens through harmful discourse. If in the second framework oppression was understood as misleading or limited knowledge about the Other, now it is detrimental and repetitive utterances that go beyond the interpersonal level. Many studies conducted through the lens of critical race theory, for example, have expressed how oppressive discourse can be to minority students. Notwithstanding, post-structuralism-one possible title for this framework-emerges as a "post-critical pedagogy" (Trifonas, 2003) and takes educators a step further in the path towards anti-oppressive education.

Kumashiro (2000) outlines four intertwined insights that post-structuralism contributes with, which have been hinted throughout this paper. First, we (and I speak particularly as a white, westerner educator) have an immanent resistance to alterity because-and this is the second insight-the presence of the Other leads the self to crisis. Going on the other direction: because "the Other is what I myself am not" (Todd, 2003, p. 3), the arrival of the Other (which can be understood as a person or an idea, for example) causes discomfort and hence "we unconsciously desire learning only that which affirms what we already know and our own sense of self" (Kumashiro, 2000, p. 43). That is why, as aforementioned, education is necessarily violent: we can only learn what we do not know, thus learning necessarily implies the decentralization of the self. The encounter with the Other follows the same logic. Consequently, welcoming the uniqueness of the Other only to the extent that they fit my existing thoughts and beliefs ultimately means not welcoming alterity at all, on the contrary, it is a totalizing act. However, a major shift in Western education is proposed by post-structuralist theorists who explain that the Other is "infinitely unknowable" (Todd, 2003, p. 3). The face of the Other, as Levinas (1982) suggested, is the representation of that which is absolutely Other, and post-structuralism invites the educator to, through self-reflexivity (third insight), be comfortable with the "presence" of the unknown, which is Kumashiro's (2000) fourth insight.

What the three previous frameworks have demonstrated is that good intentions alone are not enough to pave the way to equity and students' agency (Schroeter \& James, 2015). Tecle and James (2014), for example, provided a very pertinent critique to how racially diverse refugee students are essentialized in schools, which was discussed in the previous section. However, as a conclusion, the authors suggested that "educators must think of these students as Canadians ready, willing, and eager to make their contribution to their society" (p. 156, my emphasis)-a loop back to the boundaries of the projections of the self. Conversely, as I have argued throughout this paper, post-structuralism deconstructs longstanding constructions-to begin with the subject itself. No longer is the self the alpha, the beginning of the relation, regardless of the Other being the one who is the newcomer in the country, in the school, or in the classroom. Poststructuralism is an approach that escapes totalitarianism, that marks "the death of the good Canadian" (Richardson, 2002) rather than that of the uniqueness of Other.

\section{Opening the Door to an Ethics of Hospitality}


Despite the contributions made by Kumashiro (2000), this paper has outlined how even attempts of anti-oppressive pedagogies can fall short of welcoming the Other-which can be clearly observed when focusing on Black refugee students. When alterity is understood not as something to be sought but that which is inherent in a genuine relation, the goal becomes not to project or to understand, but to respond to the Other (Fagan, 2013; Levinas, 1982). In light of this conceptualization, the educator's responsibility when encountering the Other is the welcoming of the difference. To illustrate this idea, Derrida (2000a, 2000b) made use of the hospitality metaphor, which demonstrates to be instrumental in understanding the ethical possibilities of anti-oppressive education. There are at least three fundamental and intertwined aspects that characterize true hospitality: it is unpredictable, unconditional and uncomfortable.

First of all, true hospitality is unpredictable. Receiving a planned guest is not the proof of true hospitality. Rather, it is the one who arrives for whom I was not prepared that will put my hospitality to test: "hospitality is not merely receiving that which we are able to receive" (Derrida, 2007, p. 451). Rather, hospitality is a vertical event: we cannot anticipate it, it comes "as absolute surprise" (p. 451). On a similar vein, true hospitality is unconditional because it means receiving the one who arrives without being invited, "without asking of them either reciprocity (entering into a pact) or even their names" (Derrida, 2000a, p. 25). Consequently, this arrival is surely uncomfortable for the host, especially those who take so much pride in having everything prepared beforehand: the linen set on the bed, the toiletries in the bathroom, the warm meal on the table, the scheduled conversations. Conversely, the hospitable host is not the one who overwhelms the guest with rules and expectations; that would only make the guest uncomfortable. However, dismissing the guest, treating them as if they were not there, would make the guest feel neglected and thus unwelcome. What, then, is the duty of the host? To what extent must they act or not act?

This is one facet of the aporia of the im-possibility of responsibility: for hospitality to exist there must be a host (which implies holding mastery). But from the moment that the host says "welcome, make yourself at home", they are already conveying the message that the one who arrives is a guest, demarcating the threshold that separates them. However paradoxical this may sound, it is exactly the impossibility that makes the event possible (Derrida, 2007); hospitality is necessarily an imperfect gift. This aporia is also connected to the problem of politics: how can one be unconditionally responsible for the Other when another Other (the "Third", for Levinas $[1972,1982)]$ is also there? Finally, to add to the discomfort of the host, true hospitality involves no self-praise: the host cannot claim to have been hospitable nor that hospitality has taken place (Derrida, 2007). It is entirely up to the guest to decide whether they were welcome or not. Drawing from Levinas and Derrida, Ruitenberg (2011b, 2011a, 2016), applies the hospitality metaphor to the classroom, where the teacher is compared to a host and the student to a guest. She conceptualizes oppression as "implicitly or explicitly telling someone: "this world is not for you"' (Ruitenberg, 2016, p. 17), which can take place in different ways at different times. Its opposite, unlocking the world, or students' subjectification (Biesta, 2009), is not a one-time event either. Ruitenberg (2011b) illustrates the unpredictability of hospitable education with another metaphor: the empty chair carefully and thoughtfully placed in the classroom. The Other may or may not arrive, but if that moment comes there will be room for them. In other words, the teacher-host must invest time in preparation for the student-guest who might arrive, but in a way that intentionally engages in the deconstruction of their own planning: "Does what I am about to 
do leave a possibility for my assumptions about knowledge and teaching and learning to be upset by a new arrival? Does it close down a space for future questioning or questioners?" (Ruitenberg, 2016, p. 30). An active subject with agency is not a passive observer nor a puppet on the hands of a controlling host. Hospitality requires the guest being in the environment in their wholeness, in their uniqueness, which will then inevitably unsettle the host's habitus. The ethical challenge for educators, then, does not lie on the preparations but rather in how to respond to that "fundamentally ungraspable ... student ... in a way that lets her or him be in otherness, that does not seek to recognize or otherwise close the gap with this singular other" (Ruitenberg, 2011b, p. 32).

The usefulness of the ethics of hospitality in the pursuit social justice is briefly bespoken by Ruitenberg (2016), but without further attention specially as it relates to anti-racism education. However, anti-oppressive education under a post-structural hospitable framework both stems from the impossibility of developing rigid strategies and is sustained by it. A welcoming curriculum is not the one which gives the educator a ready-made list of pedagogical recipes. Anti-oppressive education is not "about advocating strategies that are always supposed to bring about the desired effects" (Kumashiro, 2000, p. 45). It is less about occupying the space between the self and the Other than it is about listening to the Other, in a "continual opening up toward future possibilities" (Todd, 2003, p. 133) and "say[ing] yes to who or what turns up" (Derrida, 2000a, p. 77, italics in the original). Hospitable education involves risk (Biesta, 2016; Todd, 2003). Rather than always knowing what to do, hospitable education is about undecidability (Derrida's différance), teaching with ignorance (Todd, 2003; Rancière, 1991), welcoming the unanticipated, with no expectation of reciprocity or (self-)praise for having completed the lesson plan. Consequently, this "pedagogy of discomfort recognizes and problematizes the deeply embedded emotional dimensions that frame and shape daily habits, routines, and unconscious complicity with hegemony" (Boler \& Zembylas, 2003, p. 111).

Obviously, a philosophical theory is not enough to change society. Any paradigm shift requires time (Kuhn, 1996). However, as Giroux (1981) argues, a radical pedagogy can "contribute to changing the consciousness and drives [of] the teachers and students who could then work to change society" (p.79, italics in the original). Moreover, this framework not only paves the ground for an anti-oppressive pedagogy that truly welcomes Black refugees in the classroom, but also provides the necessary shift in thought processes and tactfulness for educators in their relations with students' families. In addition, if Black refugee students are to be welcomed ethically, justice is not something that can be decided previously. As Todd (2009) observes, "justice is about securing the other's freedom to be" (p. 63), which means justice can only be done in response to the uniqueness of the Other. Black refugee students' hope of anti-racism education does not lie on preconceived notions of humanity that exclude them, but in one that welcomes them for who they are. Anti-oppressive education can only begin to take place when the decentralized teacher upholds their unconditional responsibility to each student's uniqueness. Welcoming Black refugees will not happen merely by opening the doors of the classroom to them. Neither will it happen by trying to follow a deterministic and standardized curriculum because "our institutions were designed to reproduce racial inequality and they do so with efficiency" (DiAngelo, 2018, p. 153). Rather, a truly welcoming education requires openness to the unknown Other, however uncomfortable that may be. It requires engagement with the 
discomfort of losing control over means and ends. It requires interrupting whiteness. It requires tactfulness to give space for the Other-whoever they may be, whenever they arrive-to be an active subject with agency. It requires vulnerability. It requires that which has no universal practice: it requires hospitality.

\section{References}

Addams, J. (2017). The public school and the immigrant child. In D. J. Flinders \& S. J. Thornton (Eds.), The curriculum studies reader (5th ed.) (pp. 55-57). New York, NY: Routledge.

Apple, M. (2014). Official knowledge: Democratic education in a conservative age. New York, NY: Routledge.

Asadi, N. (2014). The value of language in refugee youths' construction of identity. In C. Brewer \& M. McCabe (Eds.), Immigrant and refugee students in Canada (pp. 161-173). Edmonton, AB: Brush Education Inc.

Baker, J., Price, J., \& Walsh, K. (2016). Unwelcoming communities: Youth observations of racism in St. John's, Newfoundland and Labrador, Canada. Journal of Youth Studies, 19(1), 103-116.

Banks, J. (1993). Multicultural education: Historical development, dimensions, and practice. Review of research in education, 19(1), 3-49.

Battiste, M. (2019). Decolonizing education: Nourishing the learning spirit. Vancouver, BC: UBC press.

Biesta, G. (2009). Good education in an age of measurement: On the need to reconnect with the question of purpose in education. Educational Assessment, Evaluation and Accountability (formerly: Journal of Personnel Evaluation in Education), 21(1), 33-46.

Biesta, G. (2016). The beautiful risk of education. New York, NY: Routledge.

Bobowik, M., Basabe, N \& Darío Páez, D. (2014). "Heroes of adjustment": Immigrant's stigma and identity management. International Journal of Intercultural Relations, 41, 112-124.

Boler, M., \& Zembylas, M. (2003). Discomforting truths: The emotional terrain of understanding difference. In P. Trifonas (Ed.), Pedagogies of difference: Rethinking education for social change (pp. 110-136). New York, NY: RoutledgeFalmer.

Boulanger, D. (2019). Continuity and discontinuity of educational experience amidst school and family: Epistemological and conceptual foundations. Psychology \& Psychological Research International Journal, 4(1), 1-12.

Brewer, C., \& McCabe, M. (Eds.) (2014). Immigrant and refugee students in Canada. Edmonton, Alberta: Brush Education Inc.

Britzman, D. (1998). Lost subjects, contested objects: Toward a psychoanalytic inquiry of learning. Albany, NY: Suny Press.

Bronfenbrenner, U. (1979). The ecology of human development experiments by nature and design. Cambridge, MA: Harvard University Press.

Carson, T., \& Johnston, I. (2000). The difficulty with difference in teacher education: Toward a pedagogy of compassion. The Alberta Journal of Educational Research, 46(1), 75-83.

Clarke, G. (1997). White like Canada. Transition, 73, 98-109.

Combahee River Collective. (1977). The Combahee River Collective Statement. Retrieved from https://americanstudies.yale.edu/sites/default/files/files/Keyword\%20Coalition_Readings. pdf

Journal of Contemporary Issues in Education, 2020, 15(2), pp. 50-68. 
Dachyshyn, D., \& Kirova, A. (2011). Classroom challenges in developing an intercultural early learning program for refugee children. Alberta Journal of Educational Research, 57(2), 220-233.

Dei, G. (1996). Critical perspectives in antiracism: An introduction. Canadian Review of Sociology and Anthropology, 33(3), 247-267. Retrieved from http://gateway.webofknowledge.com/gateway/Gateway.cgi?GWVersion=2\&SrcApp=Su mmon\&SrcAuth=ProQuest\&DestApp=WOS\&DestLinkType=FullRecord\&UT=A1996 WB95600001

Dei, G. (1999). The denial of difference: Refraining anti-racist praxis. Race Ethnicity and Education, 2(1), 17-38.

Dei, G. (2000). Removing the margins the challenges and possibilities of inclusive schooling. Toronto, ON: Canadian Scholars' Press.

Dei, G. (2005). Critical issues in anti-racist research methodologies: An introduction. Counterpoints, 252, 1-27.

Dei, G. (2008). Schooling as community: Race, schooling, and the education of African youth. Journal of Black Studies, 38(3), 346-366. https://doi.org/10.1177/0021934707306570

Derrida, J. (2000a). Of hospitality. Standford, CA: Stanford University Press.

Derrida, J. (2000b). HOSTIPITALITY. Angelaki: Journal of Theoretical Humanities, 5(3), 3-18.

Derrida, J. (2007). A certain impossible possibility of saying the event. Critical Inquiry, 33(2), 441-461.

DiAngelo, R. (2018). White fragility: Why it's so hard for white people to talk about racism. Boston, MA: Beacon Press.

Donald, D. (2012). Forts, colonial frontier logics, and Aboriginal-Canadian relations: Imagining decolonizing educational philosophies in Canadian contexts. In A. Abdi (Ed.), Decolonizing philosophies of education (pp. 91-111). Rotterdam, Netherlands: Sense Publishers.

Fagan, M. (2013). Ethics and politics after poststructuralism: Levinas, Derrida and Nancy. Edinburgh, UK: Edinburgh University Press.

Fantino, A., \& Colak, A. (2001). Refugee children in Canada: Searching for identity. Child Welfare League of America, 80(5), 587-596.

Freire, P. (2017). The adulty literacy process as cultural action for freedom. In D. J. Flinders \& S. J. Thornton (Eds.), The curriculum studies reader (5th ed.) (pp. 177-192). New York, NY: Routledge.

Freire, P. (2018). Pedagogy of the oppressed. New York, NY: Bloomsbury Academic.

Freud, S. (2018). The ego \& the id. Mineola, NY: Dover.

Giroux, H. (1981). Ideology, culture and the process of schooling. Philadelphia, PA: Temple University Press.

Giroux, H. (2020). On critical pedagogy (2nd ed.). London, UK: Bloomsbury Academic. Gorski, P. (2019). Avoiding racial equity detours. Educational Leadership, 76(6), 56-61.

Gregoriou, Z. (2005). Does speaking of others involve receiving the "other"? A postcolonial reading of receptivity in Derrida's deconstruction of Timaeus. In G. Biesta \& D. EgéaKuehne (Eds.), Derrida \& education (pp. 134-149). New York, NY: Routledge.

Guo, Y., Maitra, S., \& Guo, S. (2019). “I belong to nowhere”: Syrian refugee children's perspectives on school integration. Journal of Contemporary Issues in Education, 14(1), 89-105.

Journal of Contemporary Issues in Education, 2020, 15(2), pp. 50-68. 
Hall, S. (1992). The question of cultural identity. In S. Hall, D. Held, \& A. McGrew (Eds.), Modernity and its futures (pp. 273-325). Cambridge, UK: Polity Press in association with the Open University.

Heron, B. (2007). Desire for development: Whiteness, gender, and the helping imperative. Waterloo, ON: Wilfrid Laurier University Press.

Hird-Bingeman, K., McCabe, M., \& Brewer, C. (2014). The Accelerated Basic Literacy Education (BASIC) program in the Waterloo Region District School Board. In C. Brewer \& M. McCabe (Eds.), Immigrant and refugee students in Canada (pp. 174-182). Edmonton, AB: Brush Education Inc.

hooks, b. (1994). Teaching to transgress: Education as the practice of freedom. New York, NY: Routledge.

hooks, b. (2015). Black looks: Race and representation. New York, NY: Routledge.

James, C. (2009) Re/representation of race and racism in the multicultural discourse of Canada. In A. Abdi \& L. Shultz (Eds.), Educating for human rights and global citizenship (pp. 97112). Albany, NY: SUNY Press.

Kanu, Y. (2008). Educational needs and barriers for African refugee students in Manitoba. Canadian Journal of Education / Revue Canadienne de L'éducation, 31(4), 915-940.

Kanu, Y. (2009). Changing students, changing teaching: Understanding the dynamics of adaptation to a changing student population. Cultural and Pedagogical Inquiry, 1(2), 2239.

Kuhn, T. (1996). The structure of scientific revolutions (3rd ed.). Chicago, IL: The University of Chicago Press.

Kumashiro, K. (2000). Toward a theory of anti-oppressive education. Review of Educational Research, 70(1), 25-53.

Lee, K. (2016). Using collaborative strategic reading with refugee English language learners in an academic bridging program. TESL Canada Journal, 33(10), 97-108.

Leonardo, Z. (2009). Race, whiteness, and education. New York, NY: Routledge.

Levinas, E. (1972). Humanisme de l'autre homme. Paris, FR: Le Livre de Poche.

Levinas, E. (1982). Éthique et infini. Paris, FR: Le Livre de Poche.

Levinas, E. (1997). Quelques réflexions sur la philosophie de l'hitlérisme. Paris, FR: Rivages poche/ Petite Biliothèque.

Li, X., \& Grineva, M. (2016). Academic and social adjustment of high school refugee youth in Newfoundland. TESL Canada Journal, 34(1), 51-71.

MacNevin, J. (2012). Learning the way: Teaching and learning with and for youth from refugee backgrounds on Prince Edward Island. Canadian Journal of Education / Revue Canadienne de L'éducation, 35(3), 48-63.

Maynard, R. (2017). Policing Black lives: State violence in Canada from slavery to the present. Winnipeg, MB: Fernwood Publishing.

Mbembe, A. (2017). Critique of Black reason. Durham, NC: Duke University Press.

Morris, M. (2003). Queer pedagogies: Camping up the difference. In P. Trifonas (Ed.), Pedagogies of difference (pp. 188-205). New York, NY: RoutledgeFalmer.

Noddings, N. (1984). Caring: A feminine approach to ethics and moral education. Berkeley, CA: University of California Press.

Ogbu, J. (1982). Cultural discontinuities and schooling. Anthropology \& Education Quarterly, 13(4), 290-307.

Journal of Contemporary Issues in Education, 2020, 15(2), pp. 50-68. 
Peters, M., \& Biesta, G. (2009). Derrida, deconstruction, and the politics of pedagogy. New York, NY: Peter Lang.

Pinar, W. (2017). The reconceptualization of curriculum studies. In D. J. Flinders \& S. J. Thornton (Eds.), The curriculum studies reader (5th ed.) (pp. 167-175). New York, NY: Routledge.

Porter, J. (1965). The vertical mosaic: An analysis of social class and power in Canada. Toronto, ON: University of Toronto Press.

Rabaka, R. (2013). W. E. B. Du Bois's contributions to critical race studies in education: Sociology of education, classical critical race theory, and proto-critical pedagogy. In M. Lynn \& A. Dixson (Eds.), Handbook of critical race theory in education (pp. 69-87). New York, NY: Routledge.

Rancière, J. (1991). The ignorant schoolmaster. Standford, CA: Standford University Press. Richardson, G. (2002). The death of the good Canadian. New York, NY: Peter Lang.

Ruitenberg, C. (2011a). Hospitality and subjectification: On seeing children and youth as respondents. Jeunesse: young people, texts, cultures, 3(2), 133-140.

Ruitenberg, C. (2011b). The empty chair: Education in an ethic of hospitality. Philosophy of Education Archive 2011, 28-36.

Ruitenberg, C. (2016). Unlocking the world: Education in an ethic of hospitality. New York, NY: Routledge.

Sapon-Shevin, M. (2010). Because we can change the world: A practical guide to building cooperative, inclusive classroom communities (2nd ed.). Thousand Oaks, CA: Corwin.

Schroeter, S., \& James, C. (2015). "We're here because we're Black": The schooling experiences of French-speaking African-Canadian students with refugee backgrounds. Race Ethnicity and Education, 18(1), 20-39.

Selimos, E., \& Daniel, Y. (2017). The role of schools in shaping the settlement experiences of newcomer immigrant and refugee youth. International Journal of Child, Youth and Family Studies, 8(2), 90-109.

Stewart, J. (2011). Supporting refugee children: Strategies for educators. Toronto, ON: University of Toronto Press.

Stewart, J. (2012). Transforming schools and strengthening leadership to support the educational and psychosocial needs of war-affected children living in Canada. Diaspora, Indigenous, and Minority Education, 6(3), 172-189.

Stewart, J., El Chaar, D., McCluskey, K., \& Borgardt, K. (2019). Refugee student integration: A focus on settlement, education, and psychosocial support. Journal of Contemporary Issues in Education, 14(1), 55-70.

Tavares, T., \& Slotin, I. (2012). Life after war: Education as a healing process for refugee and war-affected children. Winnipeg, MB: Manitoba Education.

Tecle, S., \& James, C. (2014). Refugee students in Canadian schools: Educational issues and challenges. In C. Brewer \& M. McCabe (Eds.), Immigrant and refugee students in Canada (pp.147-160). Edmonton, AB: Brush Education.

Tejeda, C., Espinoza, M., \& Gutierrez, K. (2003). Toward a decolonizing pedagogy: Social justice reconsidered. In P. Trifonas (Ed.), Pedagogies of difference: Rethinking education for social change (pp. 10-40). New York, NY: RoutledgeFalmer.

Todd, S. (2003). Learning from the Other: Levinas, psychoanalysis, and ethical possibilities in education. New York, NY: State University of New York Press.

Journal of Contemporary Issues in Education, 2020, 15(2), pp. 50-68. 
Trifonas, P. (2003). Toward a deconstructive pedagogy of différance. In P. Trifonas (Ed.), Pedagogies of difference: Rethinking education for social change (pp. 220-235). New York, NY: RoutledgeFalmer.

Trifonas, P. (2005). Teaching the Other II: Ethics, writing, community. In. G. Biesta \& D. EgéaKuehne (Eds.), Derrida \& education (pp. 98-118). New York, NY: Routledge.

Tyler, K., Uqdah, A., Dillihunt, M., Beatty-Hazelbaker, R., Conner, T., Gadson, N., Henchy, A., Hughes, T., Mulder, S., Owens, E., Roan-Belle, C., Smith, L., \& Stevens, R. (2008). Cultural discontinuity: Toward a quantitative investigation of a major hypothesis in education. Educational Researcher, 37(5), 280-297.

Walcott, R., \& Abdillahi, I. (2019). BlackLife: Post-BLM and the struggle for freedom. Winnipeg, MB: ARP Books.

Walker, J., \& Zuberi, D. (2019). School-aged Syrian refugees resettling in Canada: Mitigating the effect of pre-migration trauma and post-migration discrimination on academic achievement and psychological well-being. Journal of International Migration and Integration, 1-15.

Walsh, C., Este, D., Krieg, B., \& Giurgiu, B. (2011). Needs of refugee children in Canada: What can Roma refugee families tell us? Journal of Comparative Family Studies, 42(4), 599-613. https://doi.org/10.3138/jcfs.42.4.599Wilkinson, L. (2002). Factors influencing the academic success of refugee youth in Canada. Journal of Youth Studies, 5(2), 173-193.

Wilson, A. [UWinnipeg] (2016, December 6). Coming in to Indigenous sovereignty: Relationality and resurgence [Video]. YouTube. https://www.youtube.com/watch?v=XkQo_yr4A_w\&feature=emb_logo 